\section{AB021. Comparing the performance of two interferon- gamma release assays in autoimmune skin disease patients: a prospective study}

\author{
Rebecca L. Krain ${ }^{1,2}$, Rebecca G. Gaffney ${ }^{1,2}$, \\ Emily R. Keyes ${ }^{1,2}$, Rui Feng ${ }^{3}$, Victoria P. Werth ${ }^{1,2}$ \\ ${ }^{1}$ Corporal Michael J. Crescenz VAMC, Philadelphia, PA, USA; \\ ${ }^{2}$ Department of Dermatology, University of Pennsylvania, Philadelphia, \\ PA, USA; ${ }^{3}$ Department of Biostatistics and Epidemiology, University \\ of Pennsylvania, Philadelphia, PA, USA \\ Correspondence to: Victoria P. Werth. Department of Dermatology, \\ Perelman Center for Advanced Medicine, Suite 1-330A, 3400 Civic \\ Center Boulevard, Philadelphia, PA 19104, USA. \\ Email: werth@pennmedicine.upenn.edu.
}

\begin{abstract}
Autoimmune skin disease patients are standardly screened for tuberculosis (TB) via interferon-gamma release assays (IGRAs) prior to starting immunosuppressive drugs or enrolling in clinical trials. Two commercial IGRAs, T-SPOT.TB (T-SPOT) and QuantiFERONTb Gold (QFT-G), are reported as either determinate (positive or negative) or indeterminate. Both tests utilize similar immunoenzymatic reactions for interferongamma detection, but differ in quantification. Though QFT-G is more widely used, studies have demonstrated that T-SPOT has lower rates of indeterminate results in immunosuppressed patients. The newest generation of QFT-G, QuantiFERON-TB Gold Plus (QFT-Plus), has not been compared to T-SPOT in this patient population. We aim to investigate the performance of T-SPOT and QFT-Plus in autoimmune skin disease patients. This
\end{abstract}

prospective study included 48 patients. Venous blood samples were collected and underwent $\mathrm{TB}$ screening with QFT-Plus and T-SPOT IGRAs. The proportions of indeterminate and determinate results among the two tests were compared. There were 2 indeterminate results with QFT-Plus and no indeterminate results with T-SPOT. There was one positive result for QFT-Plus and T-SPOT. Using a one-tailed Fischer test, there was no statistical significance when comparing QFT-Plus and T-SPOT in autoimmune skin disease patients $(\mathrm{P}=0.25)$. Although not statistically significant, it is clinically important as indeterminate results preclude these patients from receiving necessary treatment. Compared to previous studies on QFT-G, QFT-Plus showed improvement in reducing the amount of indeterminate results. We suggest using T-SPOT in TB screening for autoimmune skin disease patients who have an indeterminate QFT-G or QFT-Plus, as this test did not display any indeterminate results.

Keywords: Autoimmune skin disease; interferon-gamma release assay; T-SPOT.TB (T-SPOT); QuantiFERON-Tb Gold (QFT-G)

doi: 10.21037/atm.2021.AB021

Open Access Statement: This is an Open Access article distributed in accordance with the Creative Commons Attribution-NonCommercial-NoDerivs 4.0 International License (CC BY-NC-ND 4.0), which permits the noncommercial replication and distribution of the article with the strict proviso that no changes or edits are made and the original work is properly cited (including links to both the formal publication through the relevant DOI and the license). See: https://creativecommons.org/licenses/by-nc-nd/4.0/.

Cite this abstract as: Krain RL, Gaffney RG, Keyes ER, Feng $\mathrm{R}$, Werth VP. Comparing the performance of two interferongamma release assays in autoimmune skin disease patients: a prospective study. Ann Transl Med 2021;9(5):AB021. doi: 10.21037/atm.2021.AB021 